\title{
A Survey on Effective in-Home Health Monitoring System
}

\author{
R.Suji Pramila \\ Department of Computer Science \& Engineering \\ Noorul Islam University \\ Tamilnadu, India
}

\author{
Shajin Nargunam, PhD. \\ Department of Computer Science \& Engineering \\ Noorul Islam University \\ Tamilnadu, India
}

\begin{abstract}
In recent years, waiting time in hospitals, emergency admissions, etc., are extremely costlier. It also increases the workload of doctors and medical professionals. Managing the cost, quality of treatment and caring for seniors are important issues in healthcare. These issues have a demand for in-home patient monitoring. Here the human body parameters are fetched by different ways through biosensors, wearable medical devices, and smart textiles. Then the collected details are forwarded to the remote server through the internet. Wearability, security, accuracy, outdoor monitoring and ease of use are some of the aspects in in-home patient monitoring system. This paper reviews the current research and development on in-home patient monitoring. A variety of system implementations were compared and evaluated to identify the technical shortcomings in the present health monitoring systems. The aim of this survey is to provide the direction for future research improvements.
\end{abstract}

\section{Keywords}

In-home patient monitoring, biosensors, wearable medical devices, smart textiles, outdoor monitoring

\section{INTRODUCTION}

In-home patient monitoring is an effective and useful research area in recent years. It provides better medical treatments even when the patient is not physically present in the hospital. This system is very useful for elderly people because they are more prone to chronic diseases and need continuous health monitoring. To support this health monitoring system, different products have been developed which provides a real time current health condition of a patient. These body parameters are forwarded directly to the caregiver or medical center. If there are any threatening health conditions, alarms are given to the ambulance. [1].

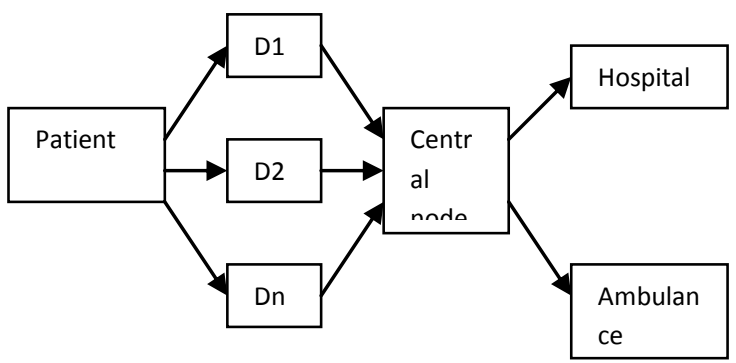

Fig 1: Architecture of wearable health monitoring system

The general architecture of wearable health monitoring system is depicted in Fig.1.This is not suitable for all the system, it varies and depends on the application. D1, D2....Dn represents different sensors or wearable medical devices. Different medical sensors are fitted on the patient's body to collect body parameters like heart rate, blood pressure, body temperature, ECG, etc. In some cases wearable medical devices or implantable devices are used to get the body details. The central node may be Personal Digital Assistant (PDA), smart phone, personal Computer (PC), microcontroller, etc.

The biosensors or wearable medical devices, which continuously collect the body parameters and sends them to the central node. The communication between sensors or wearable devices and central node is done by wireless transmission like Bluetooth, Zigbee, etc or wired transmission like conductive yarns, cables etc. The collected signals are transmitted to the hospital for further analysis. Based on the symptoms better medical treatments are given to the patient. If any abnormalities are identified then alarm signal is given to the ambulance from the central node.

In-home patient monitoring system needs to satisfy the criteria like the size and weight of the wearable devices which need to be small and should not affect the daily activities of the patient [1]. Also radiation concerns should be considered. Power consumption should be reduced and lifetime of the devices should be increased.

The effective in-home patient monitoring system should also support security and privacy concerns. That is patient's health records have sensitive data and they should be securely stored and transmitted to the remote server. Outdoor monitoring is another important aspect of patient monitoring. That is when the patient moves away from the home environment, it should not affect the monitoring process.

\section{LITERATURE SURVEY 2.1 Patient monitoring systems to ensure security}

Recently many authors proposed different schemes for ensuring security in patient monitoring systems. Confidentiality is one of the issues when storing patient related data. In [9], Cipher text Policy Attribute Based Encryption (CP-ABE) was proposed. The patient data is encrypted and decrypted based on access policy. After encrypting data, it can be stored in a server. So every one can download the copy of the data, but the access policy which was satisfied by the user can decrypt it. Here different algorithms were used to generate keys, encrypt the data and decrypt the data.

Dynamic integrity checking can be found in [14] and multiple secret sharing was used to ensure confidentiality and dependability. Orthonormal vectors were used for dynamic 
integrity checking. The main goals are confidentiality, dynamic integrity assurance and dependability. Two security issues were considered in [10]. Secure and dependable distributed data storage and fine-grained data access control. Confidentiality, integrity and dependability are the major requirements of data storage. Confidentiality is achieved by public key encryption, integrity is achieved by MAC (Message Authentication Code) schemes and dependability is achieved by error correcting codes. To achieve access control, SKC (Symmetric Key Cryptography) and PKC (Public Key Cryptography) were used. In SKC, each patient has to know all the authorized users and encrypt his own data with each user by pair wise key and it has several drawbacks. In PKC, attribute based encryption is used. $\mathrm{CP}-\mathrm{ABE}$ is the variation of $\mathrm{ABE}$. The authors concluded that $\mathrm{ABE}$ based schemes were suitable to ensure security.

In [11], data storage scheme with dynamic integrity assurance was proposed based on secret sharing and erasure coding. The data integrity schemes were based on the principle of algebraic signatures. Here the verification of data can be done without the need for original data. These schemes were secure and efficient against different types of attacks

\subsection{Health monitoring using WSN}

Wireless Sensor Network (WSN) is also used for in-home patient monitoring. A distributed telemonitoring system was proposed in [8]. It uses Services laYers over Light PHysical devices (SYLPH) model. It is a service oriented architecture model. The objective of this model was that resources to be distributed among multiple WSN and to execute over different wireless devices independently. Various networks from different wireless technologies can also be connected using this model.

In [6], Infrared (IR) sensor based system was used. IR based monitoring system was installed in house to collect motion values of the patient and different feature values like activity level, mobility level and non response level. To differentiate normal and abnormal behaviors, Support Vector Data Description (SVDD) method was used. To classify the behavior patterns, behavior pattern classification algorithm was used here. The need for a PC was eliminated in [13].The WSN was installed home. These nodes are then connected to the hospital sever through internet. Here number of sensors was used to collect only ECG signals. The ECG signals were first sampled and transmitted to the access point placed in patient's home. Then these signals were transmitted to the hospital through internet and analyzed to detect heart related diseases.

\subsection{Patient monitoring with the help of mobile phones}

Mobile phone takes important role in patient monitoring to receive, process and transmit patient details. HealthNet mobile monitoring was proposed in [7]. BSN (Body Sensor Network) embedded in clothes, collect body parameters and communicates with patient's mobile phone. Sensors and central hub were embedded in patient's shirt. The vital signals were collected by the sensors and transmit them to the central hub. Central node then communicates with mobile phone through Bluetooth link. Here confidentiality was achieved by AES128 and authentication was achieved by SHA.
A novel Wearable Mobility Monitoring System (WMMS) was introduced in [2]. This model was established based on smart phone approach. This system is easily wearable on patient's belt and it monitors patient's mobility and takes photograph during any change of state. For analysis, these photographs were used.

\subsection{Patient monitoring using Bluetooth enabled device}

Bluetooth enabled device also used for in-home patient monitoring. A Bluetooth enabled in-home patient monitoring system was proposed in [4] to detect Alzheimer disease. In the patient's home, patient carries the Bluetooth enabled monitoring device and an access point is placed in each room then all are connected to the local database. When a patient moves from one room to another, the monitoring device selects any one of the access point with strongest signal strength. Once the connection is established the current location and movement of the patient are traced and stored in a local database with the help of Bluetooth communication. The collected location information and the corresponding timestamps are forwarded to the decision engine which is placed in the hospital.

This decision engine has movement recognition software, so that the medical practitioner can perform remote diagnosis to determine whether the patient has Alzheimer's disease or not. A survey on data confidentiality in early detection of Alzheimer's disease was proposed in [12].

\section{ENABLING SECURITY AND OUTDOOR MONITORING IN WSN FOR PATIENT MONITORING 3.1 Health Monitoring Using Body Sensors}

Body sensors are used in health monitoring for acquiring body parameters continuously. Wearable sensor based health monitoring system architecture was reviewed in [1]. The bio sensors continuously acquire the physiological signals and transmit them to the central node. The central node may be PDA, smart phone, micro controller etc. Before sending to the central node the vital signs are converted into digital form if they are in analog form. The A/D converters have amplifier and filtering circuits. Bio sensors and central node are connected by any one of the wireless transmission like bluetooth, Zigbee, etc... or wired transmission like conductive yarns and cables.

The central node consists of CPU, GUI, communication and control signal module, logical signal data base and wireless transmission module. The amplified signals are received by communication and control signal module and processed by CPU then given to the wireless transmission module. This wireless transmission module transmits the signal to the medical center for analyzing or give alarm signals to an ambulance in case of any emergency.

The wireless sensor network using ECG sensors to monitor multiple patients was proposed in [16]. ECG sensors are fitted on the chest of the patient to monitor heart related information like heart rate, heart activity, etc. Here the patients are taken as nodes of the network and hospital is acting as a central node. This system consists of two modules: patient home and hospital. 
In the home module, the sensors continuously monitor the heart activity and send the signals to the Wireless Patient Portable Unit (WPPU) which is also embedded on patient's body. The WPPU is connected to the Wireless Access Point Unit (WAPU). The collected signals are sent from WPPU to WAPU then forwarded to the hospital through internet. In hospital, the received signals are stored and analyzed to detect any abnormalities. In case of any emergency the doctor contacts the patient and gives some advice or sends an ambulance to the corresponding patient's home.

\subsection{Health monitoring using smart phones}

The security architecture for health net in [7] is based on sensor network placed on clothes. It collects patient's vital signs and transmits to the mobile phone which is carried by the patient. The mobile phone securely receives, store and forward the data to the trusted medical professionals. Access of data to other parties like emergency services is controlled by patient only. Here PC is not used for processing data, but all the processes are done by mobile phones. Using data mining techniques, the unwanted data sequences are filtered and only the necessary data are transferred by the handheld device. Communication between patient's mobile and expert's device is done by Bluetooth or WLAN 802.11. In case of any emergency conditions, emergency calls are generated by patient's device and forwarded to the caregiver's device.

On demand positioning and tracking system was proposed in [3]. It is based on Global Positioning enabled devices and suitable for large environments. Smart phones between two terminals are used for making initial communication. The initial communication is performed by synchronization phase. Here requesting terminal T1 sends synchronization Short Message Service (SMS) to the requested terminal T2. If T2 refuses the message, it finishes the process. Otherwise, the location of the terminal is sent in any one of the format: text format (SMS) or multimedia format (MMS). Text format contains only the coordinate values of the terminal, but the multimedia format contains the image which represents the map of the terminal's location. The communication between two terminals is accomplished by simple Peer to Peer (P2P) protocol.

\subsection{Health monitoring with security}

Different security and privacy mechanisms were used in health monitoring. In [7], the patient's vital parameters were received, stored and transmitted by smart phone. AES-128 encryption is used between sensors to the central hub and Bluetooth encryption is used between hub and patient's mobile phone. In the handheld device, the secure data storage is achieved by AES-128 encryption. For secure data communication from handheld device to medical professional's device, AES-128 encryption and message authentication codes were used.

Different cryptographic algorithms and key sizes were proposed in [15]. Here the trusted parties were identified by 2048 bit RSA keys and certificates, 256 bit ECC keys or any shared key of at least 112 bits. The certificates are issued by certificate authority (CA). Certificate Revocation List (CRL) is used for achieving certificate revocation. CRLs are automatically generated by CA.

Cipher text Policy Attribute Based Encryption (CP-ABE) with security improvement methods were proposed in [5]. The two major problems in $\mathrm{CP}-\mathrm{ABE}$ are key escrow problem and user revocation. In $\mathrm{CP}-\mathrm{ABE}$, the private keys of users are generated by Key Generation Center (KGC) by applying set of user attributes with KGC's master secret keys. But the user cannot trust the KGC because it has the ability to decrypt the ciphertext of user if it needs to know the original data. This is known as key escrow problem. In some cases users may change their attributes frequently or some private keys are compromised. To maintain the system secure, it is necessary to update each attribute frequently. This is known as user revocation. These two problems are solved in this paper.

\section{DISCUSSION AND EVALUATION}

Some of the existing systems were reviewed to know the different methodologies used and issues identified by those systems. They are summarized in Table 1 .

\begin{tabular}{|c|c|c|}
\hline Paper title & Methodology used & Issues \\
\hline $\begin{array}{l}\text { Secure } \\
\text { Management of } \\
\text { Personal Health } \\
\text { Records by } \\
\text { Applying } \\
\text { Attribute-Based } \\
\text { Encryption [9] }\end{array}$ & $\begin{array}{l}\text { New variant of CP- } \\
\text { ABE scheme is } \\
\text { used. Data storing } \\
\text { and access control } \\
\text { mechanism is used. }\end{array}$ & $\begin{array}{l}\text { No formal } \\
\text { security proof }\end{array}$ \\
\hline $\begin{array}{lr}\text { Security } & \text { and } \\
\text { Privacy } & \text { for } \\
\text { Electronic } & \text { Health } \\
\text { Monitoring } & \text { and } \\
\text { Recording } & \\
\text { Systems[7] } & \end{array}$ & $\begin{array}{l}\text { BSN is embedded } \\
\text { in clothes, } \\
\text { communicates with } \\
\text { wearer's mobile } \\
\text { phone. Central } \\
\text { node communicates } \\
\text { with phone via } \\
\text { Bluetooth link }\end{array}$ & $\begin{array}{l}\text { No field test was } \\
\text { conducted }\end{array}$ \\
\hline $\begin{array}{l}\text { The New Secure } \\
\text { and Efficient Data } \\
\text { Storage } \\
\text { Approaches for } \\
\text { Wireless Body } \\
\text { Area } \\
\text { Networks[14] }\end{array}$ & $\begin{array}{l}\text { Uses dynamic } \\
\text { integrity checking } \\
\text { by orthonormal } \\
\text { vectors and } \\
\text { multiple secret } \\
\text { sharing to achieve } \\
\text { confidentiality and } \\
\text { dependability. }\end{array}$ & $\begin{array}{l}\text { Only data } \\
\text { storing, no access } \\
\text { control schemes }\end{array}$ \\
\hline $\begin{array}{l}\text { Data Security and } \\
\text { Privacy in } \\
\text { Wireless Body } \\
\text { Area } \\
\text { Networks[10] }\end{array}$ & $\begin{array}{l}\text { Two issues are } \\
\text { secure data storage } \\
\text { and access control. } \\
\mathrm{PKC}-\mathrm{ABE} \text { is used. }\end{array}$ & $\begin{array}{l}\text { Not satisfactorily } \\
\text { addressed the } \\
\text { security-safety } \\
\text { conflict }\end{array}$ \\
\hline $\begin{array}{l}\text { Using } \\
\text { Heterogeneous } \\
\text { Wireless Sensor } \\
\text { Networks in a } \\
\text { Telemonitoring } \\
\text { System for } \\
\text { Healthcare[8] }\end{array}$ & 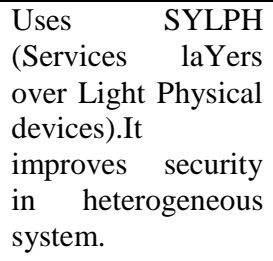 & $\begin{array}{l}\text { No decision } \\
\text { making } \\
\text { capabilities. } \\
\text { Implementation } \\
\text { in home } \\
\text { environment is } \\
\text { difficult. }\end{array}$ \\
\hline $\begin{array}{lr}\text { Detection } & \text { of } \\
\text { Abnormal } & \text { Living } \\
\text { Patterns } & \text { for } \\
\text { Elderly } & \text { Living } \\
\text { Alone } & \text { Using } \\
\text { Support } & \text { Vector } \\
\text { Data } & \\
\end{array}$ & $\begin{array}{l}\text { Uses Infrared (IR) } \\
\text { motion sensors. It } \\
\text { uses behavior } \\
\text { pattern } \\
\text { classification } \\
\text { algorithm }\end{array}$ & $\begin{array}{l}\text { Expected to be } \\
\text { applicable but no } \\
\text { proof. }\end{array}$ \\
\hline
\end{tabular}




\begin{tabular}{|c|c|c|}
\hline Description[6] & & \\
\hline $\begin{array}{l}\text { Wearable } \\
\text { Mobility } \\
\text { Monitoring Using } \\
\text { a Multimedia } \\
\text { Smart phone } \\
\text { Platform[2] }\end{array}$ & $\begin{array}{l}\text { Introduces a novel } \\
\text { wearable mobility } \\
\text { monitoring system } \\
\text { (WMMS) to detect } \\
\text { mobility. It takes } \\
\text { photographs when } \\
\text { a change in state. } \\
\text { State detection } \\
\text { algorithm is used. }\end{array}$ & $\begin{array}{l}\text { Improvement to } \\
\text { the change-of- } \\
\text { state algorithm is } \\
\text { necessary. It has } \\
\text { limited } \\
\text { performance. }\end{array}$ \\
\hline $\begin{array}{l}\text { Bluetooth- } \\
\text { Enabled In-home } \\
\text { Patient monitoring } \\
\text { System: Early } \\
\text { detection } \quad \text { of } \\
\text { Alzheimer's } \\
\text { Disease[4] }\end{array}$ & $\begin{array}{l}\text { Consists of two } \\
\text { components: in- } \\
\text { home patient } \\
\text { monitoring and } \\
\text { telediagnosis and } \\
\text { uses Bluetooth } \\
\text { communication } \\
\text { device. }\end{array}$ & $\begin{array}{l}\text { Not suitable } \\
\text { when the patient } \\
\text { moves beyond } \\
\text { the coverage area } \\
\text { of AP and no } \\
\text { security }\end{array}$ \\
\hline \begin{tabular}{lr}
\multicolumn{2}{l}{ Optimal Resource } \\
Allocation for \\
Pervasive Health \\
Monitoring \\
Systems $\quad$ with \\
Body Sensor \\
Networks[16]
\end{tabular} & $\begin{array}{l}\text { Two challenges in } \\
\text { pervasive health } \\
\text { monitoring systems } \\
\text { are sustainable } \\
\text { power supply and } \\
\text { QoS guarantee, } \\
\text { Both problems are } \\
\text { solved by } \\
\text { optimizing the } \\
\text { source rate and } \\
\text { packet scheduling } \\
\text { mechanisms }\end{array}$ & $\begin{array}{l}\text { Difficult to } \\
\text { implement on } \\
\text { WSN in home } \\
\text { environment. }\end{array}$ \\
\hline $\begin{array}{lr}\text { Wireless } & \text { Sensor } \\
\text { Networks } & \text { for } \\
\text { Monitoring } & \\
\text { Physiological } & \\
\text { Signals } & \text { of } \\
\text { Multiple } & \\
\text { Patients[13] } & \end{array}$ & $\begin{array}{l}\text { new patient } \\
\text { monitoring system } \\
\text { eliminates the need } \\
\text { for a PC.WSN is } \\
\text { designed using a } \\
\text { combination of } \\
\text { ECG sensors. }\end{array}$ & $\begin{array}{l}\text { No outdoor } \\
\text { environment } \\
\text { monitoring and } \\
\text { no security. }\end{array}$ \\
\hline $\begin{array}{l}\text { Improving } \\
\text { Security and } \\
\text { Efficiency in } \\
\text { Attribute-Based } \\
\text { Data Sharing[5] }\end{array}$ & $\begin{array}{l}\text { CP ABE is used for } \\
\text { distributed data } \\
\text { sharing. Key } \\
\text { escrow problem is } \\
\text { solved by key } \\
\text { issuing protocol } \\
\text { and user revocation } \\
\text { is done by proxy } \\
\text { encryption. }\end{array}$ & $\begin{array}{l}\text { Theoretical } \\
\text { solution only } \\
\text { provided and not } \\
\text { demonstrated in } \\
\text { distributed } \\
\text { system. }\end{array}$ \\
\hline
\end{tabular}

Table: 1 Summary of existing systems

To evaluate the existing systems some of the features are considered.

\begin{tabular}{|l|l|}
\hline Wearability & $\begin{array}{l}\text { The size and weight of the system } \\
\text { should be low }\end{array}$ \\
\hline Accuracy & $\begin{array}{l}\text { The system should provide accurate } \\
\text { results }\end{array}$ \\
\hline Security & $\begin{array}{l}\text { Secure transmission of patient's data } \\
\text { should be supported }\end{array}$ \\
\hline $\begin{array}{l}\text { Outdoor } \\
\text { monitoring }\end{array}$ & $\begin{array}{l}\text { When the patient moves out of home } \\
\text { environment it should not affect the } \\
\text { monitoring }\end{array}$ \\
\hline Ease of use & $\begin{array}{l}\text { The system should be user friendly } \\
\text { and easy to use. }\end{array}$ \\
\hline
\end{tabular}

\section{Table 2: Evaluating features}

Based on the above evaluating features, some of the existing systems have been evaluated as follows. Consider the feature value ranges from 0 to 1 . Table 3 shows the approximate evaluation

\begin{tabular}{|c|c|c|c|c|c|c|}
\hline $\begin{array}{l}\text { Existi } \\
\text { ng } \\
\text { syste } \\
\mathbf{m}\end{array}$ & $\begin{array}{l}\text { Wear } \\
\text { abilit } \\
\mathbf{y}\end{array}$ & $\begin{array}{l}\text { Accu } \\
\text { racy }\end{array}$ & $\begin{array}{l}\text { Se } \\
\mathbf{c u} \\
\text { rit } \\
\mathbf{y}\end{array}$ & $\begin{array}{l}\text { Outdo } \\
\text { or } \\
\text { monit } \\
\text { oring }\end{array}$ & $\begin{array}{l}\text { EaS } \\
\mathbf{e} \text { of } \\
\text { use }\end{array}$ & $\begin{array}{l}\text { Avera } \\
\text { ge } \\
\text { value } \\
(\%)\end{array}$ \\
\hline$[13]$ & 1 & 0.8 & 0 & 0 & 1 & 0.56 \\
\hline$[16]$ & 1 & 0.8 & 0 & 0 & 1 & 0.56 \\
\hline$[8]$ & 1 & 0.8 & 0 & 0 & 1 & 0.56 \\
\hline$[6]$ & 1 & 0.9 & 0 & 0 & 1 & 0.58 \\
\hline$[4]$ & 1 & 0.8 & 0 & 0 & 1 & 0.56 \\
\hline$[7]$ & 1 & 0.7 & 1 & 1 & 1 & 0.94 \\
\hline$[10]$ & 1 & 0.7 & 1 & 0 & 1 & 0.74 \\
\hline$[2]$ & 1 & 0.8 & 0 & 1 & 1 & 0.76 \\
\hline
\end{tabular}

Table 3: Approximate evaluation

The approximate evaluation values are plotted in column chart as shown in Fig 2. It shows that the existing system [7] satisfies most of the evaluation features. 


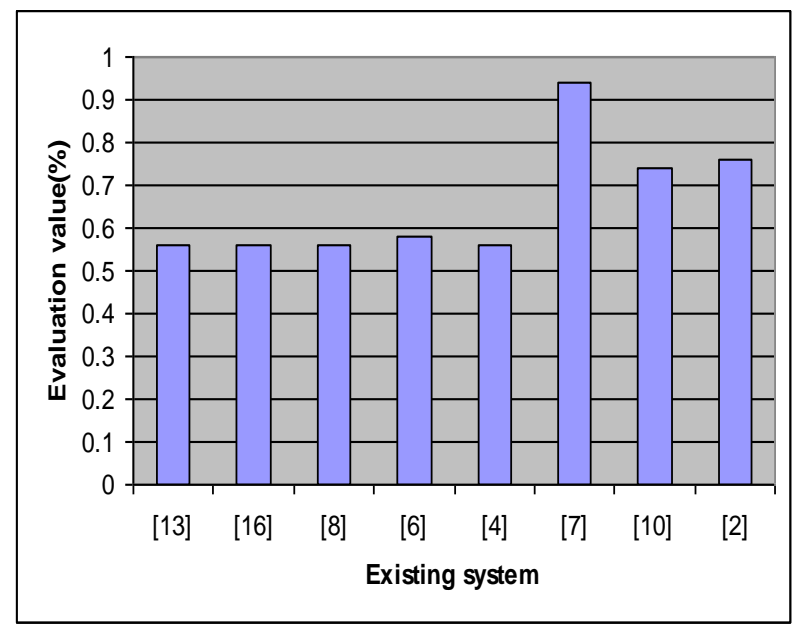

Fig 2: Evaluation graph

\section{CONCLUSION AND FUTURE ENHANCEMENT}

In-home patient monitoring with body sensor network is an effective solution for patient monitoring. It reduces the healthcare cost and waiting for a long time in hospitals. Multiple patients can be monitored at a time. The body sensors continuously collect the body parameters of the patient and they immediately forwarded that to the hospital. So it reduces the chance of false treatment and improves the quality of treatment.

The in-home patient monitoring can be effective, if it supports the outdoor environment monitoring and includes the security schemes like improved CP-ABE. Also a PC as local database can be eliminated by GPS enabled mobile phone. It can be used as local database and supports outdoor monitoring.

\section{REFERENCES}

[1] Alexandros Pantelopoulos and Nikolaos G.Bourbakis, "A Survey on Wearable Sensor-Based Systems for Health Monitoring and Prognosis", IEEE Transactions on Systems, Man and Cybernetics, Vol.40, No.1, January 2010, pp.1-12.

[2]. Gaetanne Hachette, Edward D. Lemaire and Natalie Baddour, "Wearable Mobility Monitoring Using a Multimedia Smartphone Platform" IEEE Transactions on Instrumentation and Measurement, Vol. 60, No. 9, September 2011, pp.3153-3161.

[3]. Godino et al, "P2P Multiuser Low-cost Universal Solution for On-Demand GPS Positioning and Tracking in Large Environments", IEEE Transactions on Intelligent Transportation Systems, 2011.

[4]. H. Ting and W. Zhuang, "Bluetooth-Enabled In-home Patient Monitoring System: Early Detection of
Alzheimer's disease," IEEE Wireless Comm., Feb. 2010, pp. 74-79.

[5]. J. hur, "Improving Security and Efficiency in AttributeBased Data Sharing," IEEE Transactions on Knowledge and Data Engineering. IEEE 2011

[6]. Jae Hyuk Shin, Boreom Lee, and Kwang Suk Park, "Detection of Abnormal Living Patterns for Elderly Living Alone Using Support Vector Data Description," IEEE Transactions on Information Technology in Biomedicine, Vol. 15, No. 3, May 2011, pp.438-448.

[7]. Johannes Barnickel, Hakan Karahan, Ulrike Meyer, "Security and Privacy for Mobile Electronic Health Monitoring and Recording Systems" IEEE 2010.

[8]. Juan M. Corchado, Javier Bajo, Dante I. Tapia, and Ajith Abraham, "Using Heterogeneous Wireless Sensor Networks in a Telemonitoring System for Healthcare," IEEE Transactions on Information Technology in Biomedicine, Vol. 14, No. 2, March 2010, pp.234-240.

[9]. Luan Ibraimi, Muhammad Asim, Milan Petko vic, "Secure Management of Personal Health Records by Applying Attribute-Based Encryption," IEEE 2010.

[10].M. Li and W. Lou," Data Security and Privacy in Wireless Body Area networks," IEEE Wireless Comm., Feb. 2010, pp. 51-58.

[11].Qian Wang and Kui Ren Wenjing Lou Yanchao Zhang, "Dependable and Secure Sensor Data Storage with Dynamic Integrity Assurance", IEEE INFOCOM 2009, pp.954-962.

[12]. R. Suji Pramila, A. Shajin Nargunam, "A Study On Data Confidentiality In early Detection Of Alzheimer's Disease," IEEE 2012, pp.1004-1008.

[13].Reza S. Dilmaghani, Hossein Bobarshad, M. Ghavami, Sabrieh Choobkar, and Charles Wolfe, "Wireless Sensor Networks for Monitoring Physiological Signals of Multiple Patients," IEEE Transactions on biomedical circuits and systems, vol. 5, no. 4, august 2011, pp.347356.

[14].Rong Fan, Ling-Di Ping, Jian-Qing Fu, Xue-Zeng Pan, "The New Secure and Efficient Data Storage Approaches for Wireless Body Area Networks," IEEE 2010.

[15].W.T.Polk, D.K.Dodson and W.E.Burr, "Draft: Cryptographic algorithms and key sizes for personal identification verification (PIV).” In NIST Special Publication 800-78-2, 2009.

[16].Yifeng He, Wenwu Zhu and Ling Guan, "Optimal Resource Allocation for Pervasive Health Monitoring Systems with Body Sensor Networks", IEEE Transactions on Mobile Computing, Vol.10, No.11, November 2011, pp.1558-1575. 